\title{
Congenital Atrophoderma of Pasini and Pierini
}

\begin{abstract}
Idiopathic atrophoderma of Pasini and Pierini is a form of dermal atrophy of unknown etiology, usually affecting women during their adolescence and young adulthood. A 2-yr-old girl was presented with erythematous atrophic lesion on the right shoulder, which appeared from birth. The histologic findings were consistent with atrophoderma. This patient, to the best of our knowledge, is the first case of atrophoderma with an onset since birth.
\end{abstract}

Key Words : Atrophy; Dermis; congenital

\section{Sung Kwon Kim, Seung Ho Rhee, You Chan Kim, Eun-So Lee, Hee Young Kang}

Department of Dermatology, Ajou University School of Medicine, Suwon, Korea

Received : 26 October 2004

Accepted : 20 December 2004

\section{Address for correspondence}

Hee Young Kang, M.D.

Department of Dermatology, Ajou University School of Medicine, 5 Wonchon-dong, Yeongtong-gu, Suwon

443-721, Korea

Tel : +82.31-219-5190, Fax : +82.31-219-5189

E-mail : hykang@ajou.ac.kr

\section{INTRODUCTION}

Idiopathic atrophoderma of Pasini and Pierini (IAPP) is a localized form of dermal atrophy seen typically seen as several oval, hyperpigmented, atrophic plaques developing on the trunk. The lesion usually affects women during their adolescence and young adulthood (1). In this report, we present an unusual case of atrophoderma of Pasini and Pierini with an onset since birth.

\section{CASE REPORT}

A 2-yr-old girl was presented with erythematous atrophic lesion on the right shoulder, which appeared since birth. The size of lesion was slowly growing but the shape, color, or texture of the lesion had not changed since first being discovered. Her family and medical history was unremarkable. On physical examination, she had slightly depressed erythematous plaques on the right shoulder (Fig. 1). There was no induration on the lesion. Punch biopsy for microscopic examination was done from the lesional and adjacent normal-appearing skin for comparison. Histopathological examination of a specimen from the involved skin showed markedly reduced dermal thickness when compared with adjacent normal skin (Fig. 2A, B). The collagen bundles in the dermis were slightly homogenized in appearance (Fig. 2C). The elastic tissue stain showed no abnormality.

\section{DISCUSSION}

IAPP is a form of dermal atrophy, which mostly affects women during their adolescence and young adulthood (2). In one report, of the 40 cases 26 were women and 14 were men, giving a female/male ratio of $2: 1$. The mean age of patients was $30 \mathrm{yr}$, although patients have been as young as $7 \mathrm{yr}$ and as old as $66 \mathrm{yr}$ at initial presentation. And 8 of the 40 cases developed before the age of $13 \mathrm{yr}$ (3). However, none have been reported to occur with congenital lesion like our patient. The lesions are single or multiple, usually round or ovoid in shape. The affected skin is usually brown or blue to violet in color and the surface of the skin is normal in appearance with a lack of induration (4). It usually occurs on the trunk, especially on the back and lumbosacral region. Other frequently involved sites are the chest, arms, and abdomen (5). It occurs usually bilaterally and symmetrically in distribution (6). However, unilateral involvement like our case has been reported (7).

Different opinions have been suggested whether IAPP is a variant of morphea or a separate distinct entity. Recently IAPP has been regarded as a superficial form of localized morphea. It is favored by similar clinical and histological features. Lesions of "burn-out" morphea may be atrophic similar to that of IAPP (8) and some histologic similarities such as mild sclerosis and collagen homogenization exist in a few cases $(1,9)$. There was a case report of a patient with typical IAPP who developed progressive systemic sclerosis (10). However, whether this disorder is an end stage of morphea is unclear. Some clinicians regard IAPP as a distinct 
entity on the basis of the following reasons. IAPP does not show the typical lilac ring of morphea and IAPP progresses for a longer duration than morphea $(1,8)$. In addition, the lesions of IAPP are characterized by atrophy without any indurations, whereas morphea begins with indurations and ultimately results in atrophy $(1,11)$. Moreover, histological findings such as dermal atrophy and usual absence of dermal sclerosis of IAPP are different from those of morphea (1). A report that analyzed glycosaminoglycans in IAPP and morphea showed decreased amount of glycosaminoglycans in

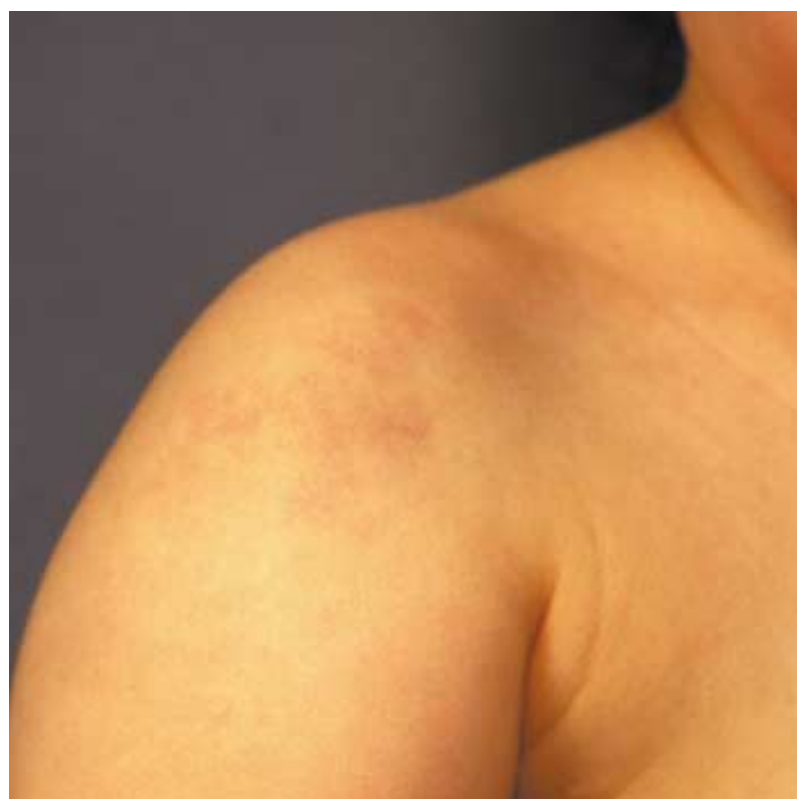

Fig. 1. Atrophic erythematous plaques on the right shoulder.
IAPP but increased amount in morphea, which suggests that glycosaminoglycans metabolism in IAPP may be unique and quite different from that in morphea (12). From this point of view, our patient could be diagnosed as IAPP. She had atrophic lesions without indurations. And the histological findings showed a significant decrease in dermal thickness when compared with adjacent normal skin, which were consistent with the findings of IAPP.

In summary, IAPP can be presented with a congenital onset and thus should be considered in the differential diagnosis of congenital skin lesions.

\section{REFERENCES}

1. Canizares O, Sachs PM, Jaimovich L, Torres VM. Idiopathic atrophoderma of Pasini and Pierini. AMA Arch Dermatol 1958; 77: 42-58.

2. Pullara TJ, Lober CW, Fenske NA. Idiopathic atrophoderma of Pasini and Pierini. Int J Dermatol 1984; 23: 643-5.

3. Stanislaw AB, Theo R. Atrophoderma of Pasini and Pierini. J Am Acad Dermatol 1994; 30: 441-6.

4. Catherine M, Julie P. Idiopathic Atrophoderma of Pasini and Pierini. In: Jean LB, Joseph LJ, Ronald PR, editors, Dermatology, Vol.2. New York: Mosby, 2003; 1544-8.

5. Beuchner SA, Rufli T. Atrophoderma of Pasini and Pierini: clinical and histopathological findings and antibodies to Borrelia burgdorferi in thirty four patients. J Am Acad Dermatol 1994; 30: 441-6.

6. Jaworsky C. Connective tissue diseases. In: Elder D, Elenitsas R, Jaworsky C, Johnson B, editors, Lever's Histopathology of the Skin, 8th edn. Philadelphia: Lippincott-Raven Co., 1997; 278-9.

7. Iriondo M, Bloom RF, Neldner KH. Unilateral atrophoderma of
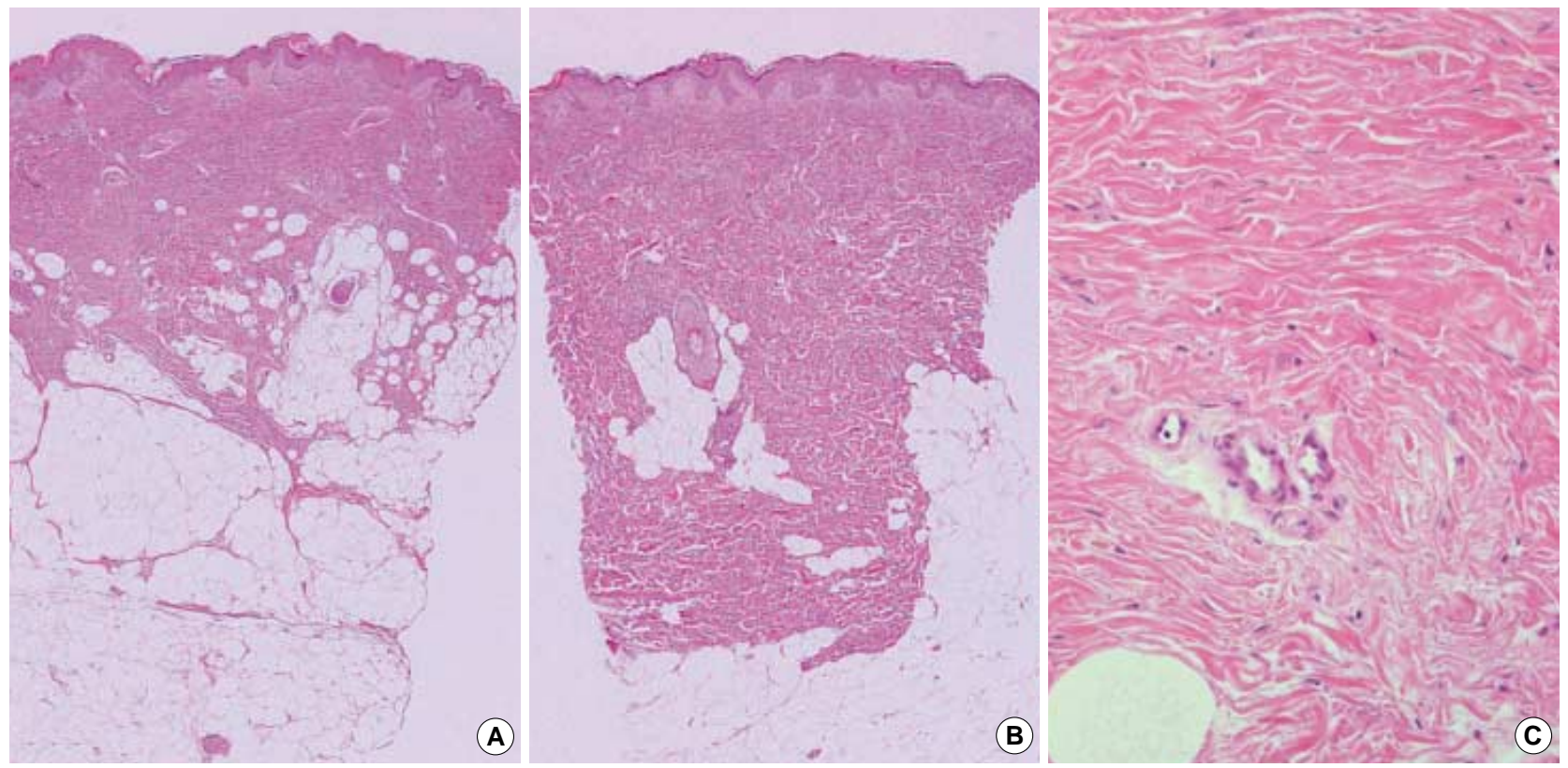

Fig. 2. The involved skin (A) showed markedly reduced dermal thickness when compared with adjacent normal skin (B); hematoxylin-eosin stain, $\times 40$. The collagen bundles in the dermis of the lesion are slightly homogenized in appearance $(\mathrm{C})$; hematoxylin-eosin stain, $\times 400$. 
Pasini and Pierini. Cutis 1987; 39: 69-70.

8. Poche GW. Progressive idiopathic atrophoderma of Pasini and Pierini. Cutis 1980; 25: 503-6.

9. Miller RF. Idiopathic atrophoderma. Arch Dermatol 1965; 92: 653-60.

10. Bisaccia EP, Scarborough DA, Lowney ED. Atrophoderma of Pasini and Pierini and systemic scleroderma. Arch Dermatol 1982; 118: 1-2.
11. Eshelman O. Idiopathic atrophoderma of Pasini and Pierini. Arch Dermatol 1965; 92: 737-8.

12. Yokoyama Y, Akimoto S, Ishikawa O. Disaccharide analysis of skin glycosaminoglycan in atrophoderma of Pasini and Pierini. Clin Exp Dermatol 2000; 25: 436-40. 